\title{
The importance of synchronization among different but complementary medical departments about unresolved issues
}

\author{
Nurdan Cay $\cdot$ Ozgur Tosun
}

Received: 19 March 2013/Accepted: 29 March 2013/Published online: 6 April 2013

(C) Springer-Verlag France 2013

We have read with great interest the article entitled 'Quantitative assessment of the ischiofemoral space and evidence of degenerative changes in the quadratus femoris muscle' by Sussman et al. [2] in the recent online issue of the journal. The authors have stated that in some situations, the exact etiology of the groin pain cannot be found. Therefore, the ischiofemoral (IF) space and pathologies affecting quadratus femoris (QF) muscle might be responsible from these unexplained situations [1, 3].

The diagnosis of IF impingement is related with both clinical and imaging findings. Narrowing of the IF space and/or loss of homogeneity of QF muscle are not always related with impingement. Nowadays, the assessment of this anatomical region in symptomatic patients is made by magnetic resonance imaging which has the ability of showing both the bony and the soft tissues together. Therefore, physical examination of the patient should be made by professional hands, and the radiologist examining the anatomical region should have detailed knowledge about normal anatomy and pathologic changes.

In our previously published study, we have found that statistically significant difference was present between the study $(n=70)$ and the control $(n=38)$ groups regarding the spaces of IF and QF in the neutral position [4]. For IF space, the ranges were $12.72-13.05$ and $21.61-22.29 \mathrm{~mm}$ and for QF space, the ranges were 6.56-6.91 and $13.35-13.59 \mathrm{~mm}$. In addition, narrowing of the space was

\footnotetext{
N. Cay $\cdot$ O. Tosun

Department of Radiology, Ataturk Education and Research Hospital, Ankara, Turkey

N. Cay $(\bowtie)$

Yasamkent Mah. 3222. Cad., Besa Karina Evleri 2. Blok (Yakut), No: 37 D: 27 Cayyolu, 06810 Ankara, Turkey

e-mail: nurdancay@yahoo.com
}

significantly related with edematous and fatty degenerations in the QF muscle [4].

Because of small sample size of the study and the control groups in the study of Sussman et al. [2], the projection of measured values to entire population cannot be performed. In addition, other limitations of their study were to be a cadaveric study, no information about clinical findings, and not enough movement ability of the cadaveric specimens. However, the importance of this issue to be addressed by anatomists emphasized the importance one more time.

In conclusion, we think that departments of radiology and anatomy complete each other, especially about less known issues. Therefore, further joint studies should be designed about unresolved issues.

Conflict of interest The authors declared no potential conflicts of interest with respect to the research, authorship, and/or publication of this article.

\section{References}

1. Johnson KA (1977) Impingement of the lesser trochanter on the ischial ramus after total hip arthroplasty. Report of three cases. J Bone Joint Surg Am 59:268-269

2. Sussman WI, Han E, Schuenke MD (2012) Quantitative assessment of the ischiofemoral space and evidence of degenerative changes in the quadratus femoris muscle. Surg Radiol Anat. doi: 10.1007/s00276-012-1029-5

3. Torriani M, Souto SC, Thomas BJ, Ouellette H, Bredella MA (2009) Ischiofemoral impingement syndrome: an entity with hip pain and abnormalities of the quadratus femoris muscle. AJR Am J Roentgenol 193:186-190

4. Tosun O, Algin O, Yalcin N, Cay N, Ocakoglu G, Karaoglanoglu M (2012) Ischiofemoral impingement: evaluation with new MRI parameters and assessment of their reliability. Skeletal Radiol 41:575-587 